\title{
Microarray analysis of RNA extracted from formalin-fixed, paraffin-embedded and matched fresh-frozen ovarian adenocarcinomas
}

\author{
Grazyna Fedorowicz'1, Steve Guerrero², Thomas D Wu² and Zora Modrusan*1
}

Address: ${ }^{1}$ Department of Molecular Biology, Genentech, Inc., 1 DNA Way, South San Francisco, CA 94080, USA and ${ }^{2}$ Department of Bioinformatics, Genentech, Inc., 1 DNA Way, South San Francisco, CA 94080, USA

Email: Grazyna Fedorowicz - fedorowicz.grazyna@gene.com; Steve Guerrero - guerrero.steve@gene.com; Thomas D Wu - wu.thomas@gene.com; Zora Modrusan* - modrusan.zora@gene.com

* Corresponding author

Published: 8 May 2009

BMC Medical Genomics 2009, 2:23 doi:10.1 186/1755-8794-2-23

This article is available from: http://www.biomedcentral.com/I755-8794/2/23

(c) 2009 Fedorowicz et al; licensee BioMed Central Ltd.

This is an Open Access article distributed under the terms of the Creative Commons Attribution License (http://creativecommons.org/licenses/by/2.0), which permits unrestricted use, distribution, and reproduction in any medium, provided the original work is properly cited.

\begin{abstract}
Background: Gene expression profiling of formalin-fixed, paraffin-embedded (FFPE) samples represents a valuable approach for advancing oncology diagnostics and enhancing retrospective clinical studies; however, at present, this methodology still requires optimization and thus has not been extensively used. Here, we utilized thorough quality control methods to assess RNA extracted from FFPE samples and then compared it to RNA extracted from matched fresh-frozen (FF) counterparts. We preformed genome-wide expression profiling of FF and FFPE ovarian serous adenocarcinoma sample pairs and compared their gene signatures to normal ovary samples.
\end{abstract}

Methods: RNA from FFPE samples was extracted using two different methods, Ambion and Agencourt, and its quality was determined by profiling starting total RNA on Bioanalyzer and by amplifying increasing size fragments of beta actin (ACTB) and claudin 3 (CLDN3) by reversetranscriptase polymerase chain reaction. Five matched FF and FFPE ovarian serous adenocarcinoma samples, as well as a set of normal ovary samples, were profiled using whole genome Agilent microarrays. Reproducibility of the FF and FFPE replicates was measured using Pearson correlation, whereas comparison between the FF and FFPE samples was done using a Z-score analysis.

Results: Data analysis showed high reproducibility of expression within each FF and FFPE method, whereas matched FF and FFPE pairs demonstrated lower similarity, emphasizing an inherent difference between the two sample types. Z-score analysis of matched FF and FFPE samples revealed good concordance of top 100 differentially expressed genes with the highest correlation of 0.84 . Genes characteristic of ovarian serous adenocarcinoma, including a well known marker CLDN3, as well as potentially some novel markers, were identified by comparing gene expression profiles of ovarian adenocarcinoma to those of normal ovary.

Conclusion: Conclusively, we showed that systematic assessment of FFPE samples at the RNA level is essential for obtaining good quality gene expression microarray data. We also demonstrated that profiling of not only FF but also of FFPE samples can be successfully used to identify differentially expressed genes characteristic of ovarian carcinoma. 


\section{Background}

According to the American Cancer Society, ovarian cancer is the fifth leading cause of cancer deaths in women in the United States. The most common, epithelial, type of ovarian cancer can be divided into several subtypes including: serous, endometrioid, mucinous, clear cell and undifferentiated. Serous adenocarcinoma comprises majority of cases and exhibits a poor 5-year survival rate. Up to $90 \%$ of ovarian cancers might be cured if identified in an early stage. When diagnosed in later stages, the rate drops significantly to a range of $30-50 \%$. Detection of ovarian cancer is often delayed or missed because of a lack of clear symptoms and absence of reliable diagnostic methods. Cancer marker 125 (CA125), the product of mucin 16, is currently used for testing patients with elevated risk of ovarian cancer. However, this marker alone does not provide the required sensitivity or specificity to detect all cases [1]. Another gene, claudin 3 (CLDN3), has been found to be highly expressed at gene and protein levels and thus has been suggested as a reliable marker of ovarian cancer [2-5].

Large repositories of formalin-fixed, paraffin-embedded (FFPE) samples are available and could be used to identify markers for diagnosis of many diseases. While tissue integrity in FFPE specimens is often better preserved than in matched fresh-frozen (FF) counterparts, the quality of nucleic acids in FFPE samples is far from optimal due to chemical crosslinking and nucleic acid fragmentation [68]. Despite the detrimental effect of the fixative, numerous studies using archived FFPE samples have generated satisfactory reverse-transcriptase polymerase chain reaction (RT-PCR) data [9-13]. Recently, a number of genomewide microarray studies has been conducted to investigate gene expression in FFPE samples or to compare the performance of FFPE samples with their matched FF counterparts [14-23]. While the results of some studies are discouraging $[16,19]$, many archived FFPE samples have been successfully used to identify prognostic and diagnostic gene signatures for numerous diseases, including various carcinomas [21-24].

\section{Methods \\ Samples}

Matched FF and FFPE samples were obtained from five ovarian serous adenocarcinoma patients. Samples 3136, 3138,3194 and 3207 were collected on $11 / 2004,11 /$ 2004, 05/2005, and 06/2005, respectively. A portion of each sample was either frozen at $-80^{\circ} \mathrm{C}$ until extraction or fixed within 30 minutes of surgery by incubation in $10 \%$ neutral-buffered formalin (NBF) for $4-18$ hours at $4{ }^{\circ} \mathrm{C}$. Patient sample 390 was collected on 01/2005 and was either frozen or fixed for 24 hours at room temperature in $10 \%$ NBF within 30 minutes of surgery. Only tumor samples containing minimal necrosis $(<10 \%)$ and consisting of $70 \%$ or more tumor cells were used in this study. A set of normal ovary samples was obtained from different patients by dissecting normal tissue adjacent to tumors. All tumor and normal ovary samples were acquired commercially by the Human Tissue Lab at Genentech.

\section{RNA extraction methods \\ FF samples}

Three 10-micron sections were homogenized individually and RNA was extracted using the RNeasy Lipid Tissue Mini Kit (Qiagen, San Diego, CA). Replicate RNA preps were pooled to obtain sufficient amounts of starting material. For normal ovary samples, RNA was extracted using Qiagen's ALLPrep method that included on-column DNase treatment.

\section{FFPE samples}

After evaluating four FFPE RNA extraction methods (Invitrogen PureLink, Ambion RecoverAll, Ambion Optimum and Agencourt FormaPure; data not shown), the Optimum FFPE RNA Isolation Kit (Ambion, Austin, TX) and the FormaPure Kit (Agencourt, Beverly, MA) were selected for this study based on their potential to generate the most abundant population of high molecular weight RNA fragments. The two methods were used to extract RNA from five archived FFPE ovarian serous adenocarcinoma samples. Up to eight 10-micron FFPE sections were processed per patient. Ambion's RNA extraction procedure was optimized for maximum RNA recovery (Susanna Stinson, Genentech, Inc., personal communication) by elevating the temperature of the first $10 \mathrm{~min}$ deparaffinization to $55^{\circ} \mathrm{C}$ and digesting the samples for 3 hours at $55^{\circ} \mathrm{C}$. After adding a fresh aliquot of Proteinase $\mathrm{K}$, the samples were digested for an additional hour at $55^{\circ} \mathrm{C}$. The Agencourt protocol was followed without any modifications. DNase treatment was applied to both FF and FFPE samples and was followed by phenol:chloroform:isoamyl alcohol purification and ethanol precipitation.

\section{Quality control methods}

The quantity of RNA and labeled cRNA was measured using Nanodrop ND-1000 UV-spectrophotometer (NanoDrop Technologies, Wilmington, DE). Specific activity of cRNA, calculated as picomoles of Cy5 dye per microgram $(\mu \mathrm{g})$ of cRNA, was also measured by Nanodrop. Sample integrity was evaluated by profiling both RNA and cRNA on Agilent 2100 Bioanalyzer (Agilent Technologies, Santa Clara, CA).

RNA integrity was determined by amplifying different length fragments ( 200, 400, 600 and 800 basepairs (bp)) of beta actin (ACTB) and CLDN3 genes using Qiagen's OneStep RT-PCR kit protocol. The following 5'-3' primers were used to amplify ACTB [GenBank:NM_001101]: 200 F GGTGATAGCATTGCTTTCGTGTAA，400 F CAGTCG- 
GTTGGAGCGAGCATCC， 600 F CTCCATCGTCCACCGCAAATGC, 800 F GGCACCACCATGTACCCTGGCA and R TCAAGTCAGTGTACAGGTAAGCC. The following 5'-3' primers were used to amplify CLDN3 [GenBank: NM 001306]: 200 F CCATCCAGCGTGCAGCCTTGC, 400 F GCTGCTCTGCTGCTCGTGTCC, 600 F CCAAGATCACCATCGTGGCAGG, 800 F GCCTGTGGATGAACTGCGTGG and R AGTATTGGCGGTCACCCAGGC. Five nanograms of RNA were used as a template for reverse transcription $\left(30 \mathrm{~min}\right.$ at $50^{\circ} \mathrm{C}$ ), followed by activation of the HotStarTaq polymerase $\left(15 \mathrm{~min}\right.$ at $\left.95^{\circ} \mathrm{C}\right), 35$ cycles of PCR $\left(30 \mathrm{sec}\right.$ at $95^{\circ} \mathrm{C}, 30 \mathrm{sec}$ at $60^{\circ} \mathrm{C}$, and $1 \mathrm{~min}$ at $72^{\circ} \mathrm{C}$ ), and final $10 \mathrm{~min}$ extension at $72^{\circ} \mathrm{C}$. Each fragment was amplified individually; however, all of them were pooled and electrophoresed in a single lane. PCR products were visualized on 4\% agarose e-gels (Invitrogen, Carlsbad, CA). SimplyLoad 100 bp DNA Ladder (Lonza, Basel, Switzerland) was used to determine product size.

\section{Microarrays}

Total RNA was labeled according to Agilent's Low RNA Input Fluorescent Linear Amplification Kit. The test samples (i.e. RNA from FF and FFPE samples) were labeled with the Cy5 dye and the reference sample (i.e. Universal Human Reference, Stratagene, La Jolla, CA) was labeled with the Cy3 dye. Matched FF samples (5 patients, 2 replicates) and FFPE samples extracted using either the Agencourt method ( 5 patients, 3 replicates for 3136, 3138 and 3194, 2 replicates for 3207 and 390) or the Ambion method ( 5 patients, no replicates) were hybridized to Agilent Whole Human Genome $4 \times 44 \mathrm{~K}$ microarrays according to the manufacturer's protocol. Microarray images were analyzed using Agilent's Feature Extraction (FE) software, version 9.5.

\section{Data analysis}

Reproducibility of the FF and FFPE sample types was measured using Pearson correlations (r). Only "passing" probes were included in this analysis, where "passing" consisted of probes that were not recognized as outliers by the FE software, were significantly above background, and had a P value of the Cy5/Cy3 ratio below 0.05. We compared results between sample types (frozen versus fixed) by applying a Z-score analysis [25] to the four samples whose quality was adequate for microarray profiling $(3136,3138,3194$, and 3207). For small data sets, the Zscore technique provides a method for determining genes that have significantly different expression in a single sample relative to other samples. These scores indicate the degree of deviation from the mean, in terms of the number of standard deviations, and they are likely to reveal well-behaving probes because they impose two requirements: a large deviation in one sample compared to the remaining samples, indicating a likely true biological difference in expression, and a small standard error, indicating that the probe set gives consistent measure- ments in the remaining n-1 samples. Before the Z-score analyses were applied, we computed geometric means of relevant replicate measurements for the two groups: FF tumor (4 patients, excluding sample 390) and FFPE-Agencourt tumor (4 patients, excluding sample 390). FFPEAmbion tumor samples were not included in the Z-score analysis. We then computed Z-scores for each FFPE sample relative to the remaining three FFPE samples with a constant factor of 1 added to the denominator to avoid situations where the standard error was spuriously close to zero. For comparison, we also computed Z-scores using the same methodology for each of the FF samples relative to the other three FF samples. We then evaluated three criteria for filtering data from the FFPE samples. First, we considered all probes assayed on the array. Second, we considered only those probes where the Cy5 channel had a value of 1000 or greater ("1000 Cy5"). Finally, we considered top 100 differentially expressed probes that were both " 1000 Cy5" and had the largest Z-scores, namely, the top 50 positive and top 50 negative Z-scores ("100 DE"). For each matched pair, we compared the selected FFPE Zscores with corresponding FF Z-scores. Furthermore, for each of these three criteria, we evaluated correlation both quantitatively and qualitatively. The quantitative comparison measured the Pearson correlations of the Z-scores between the FFPE and FF samples. For the qualitative comparison, we tallied the "100 DE" probes whose signs of the FFPE Z-scores were the same as or opposite of the corresponding FF scores. The reported misclassification rates reflect the number of opposite-sign probes as a fraction of the total 100 probes.

Identification of genes that were differentially expressed in serous adenocarcinoma compared to normal ovary was achieved by a stepwise analysis. First, probes "passing" in all replicates of the four groups including FF, FFPE-Agencourt, and FFPE-Ambion tumors (see replicate details above) and FF normal samples (5 patients, 2 replicates per patient) were selected. Replicate Cy5/Cy3 ratios for each passing probe were averaged within a method before performing the Cyber t-test [26]. This t-test compared Cy5/ Cy3 $\log _{10}$ ratios of FF tumor $(n=5)$ vs normal $(n=5)$ and FFPE tumor $(n=4)$ vs normal $(n=5)$; only probes with $P$ values of equal to or less than 0.05 were considered further. All patient samples within a method were then averaged by calculating geometric means of the Cy5/Cy3 ratios for the genes that passed the two previous criteria ("passing" and t-test P value cutoff of 0.05). The resulting tumor-to-normal ratios are reported, where the ratio is at least 2-fold higher in all tumors than in all normals.

\section{Results Quality assessment of FF and FFPE samples}

Following RNA quantification using Nanodrop, Agilent 2100 Bioanalyzer was utilized to generate RNA profiles for all FF and FFPE matched pairs (Figure 1A). FF samples 
A

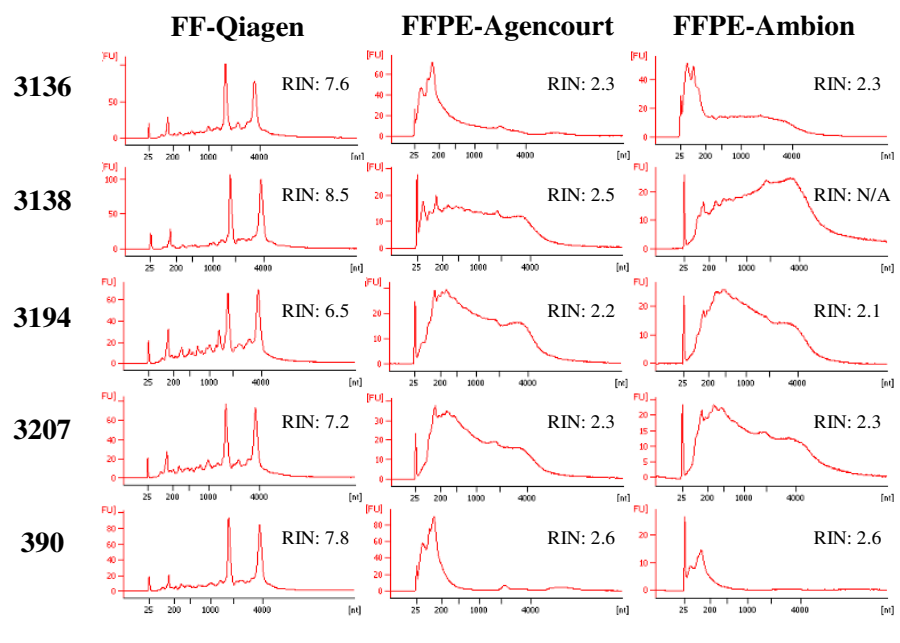

B

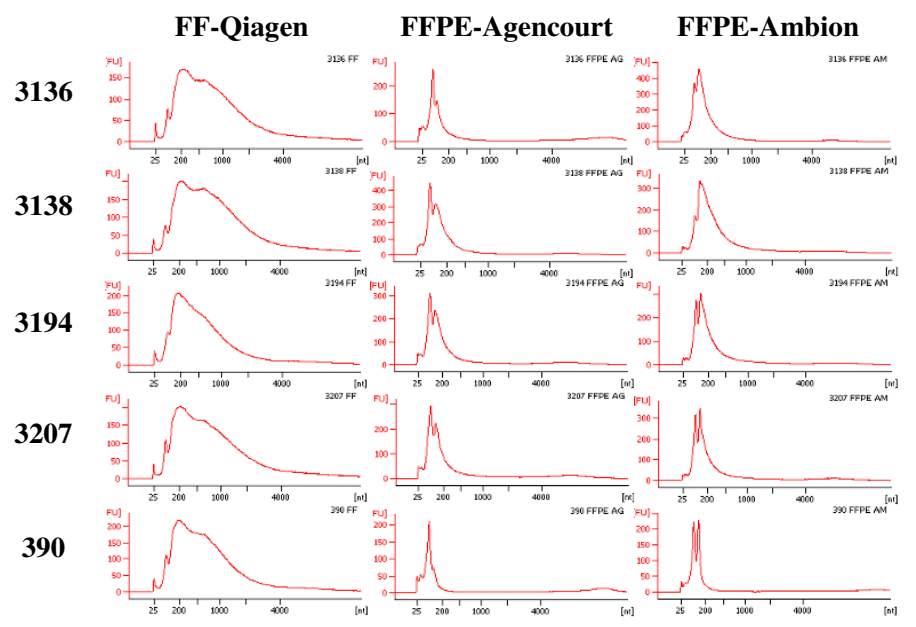

\section{Figure I}

Bioanalyzer profiles of total RNA (A) and cRNA (B) of matched FF and FFPE ovarian serous adenocarcinoma samples 31 36, 3 I38, 3 I 94, 3207 and 390. The method used for RNA extraction (Qiagen, Agencourt, Ambion) is indicated for each sample type. The RNA Integrity Number (RIN) is shown next to each total RNA profile.

showed high quality of RNA; $18 \mathrm{~S}$ and $28 \mathrm{~S}$ ribosomal peaks were present in all samples giving RNA Integrity Numbers (RINs) from 6.5 to 8.5. In contrast, the landmark ribosomal peaks were not detected in any of the FFPE samples, resulting in lower RINs. Since RINs depend on the presence of ribosomal peaks in the RNA samples, they can not accurately reflect the quality of FFPE RNA. For example, the most degraded sample 390 showed the highest RINs among all FFPE samples. RNA profiles obtained from the FFPE samples were similar for the two RNA extraction methods. FFPE samples 3138, 3194, and 3207 exhibited desirable profiles with elevated levels of high molecular weight RNAs. In contrast, small molecular weight RNAs were recognized as a sharp peak between 25 and 200 nucleotides (nt); the peak was the most prominent feature in samples 3136 and 390 . Closer comparison between these two samples revealed that sample 3136 contained relatively low level of high molecular weight RNA fragments, while a flat electropherogram beyond $500 \mathrm{nt}$ suggests absence of such RNA fragments in sample 390. Based on these results, FFPE sample 390 was classified as having inadequate RNA quality; this was surprising since slide examination indicated that it contained well preserved tissue.

Additional quality assessment of total RNA obtained from matched FF and FFPE samples was done by RT-PCR amplification of different length fragments of ACTB and $C L D N 3$ genes. As expected, RNA from FF samples resulted in amplification of all fragment sizes (Figure 2). The largest amplicon, $800 \mathrm{bp}$, was observed only in FF samples, suggesting that intact RNA of such length was rare in FFPE samples. RNA extracted from FFPE sample 390 failed to produce any $A C T B$ and CLDN3 fragments (data not 


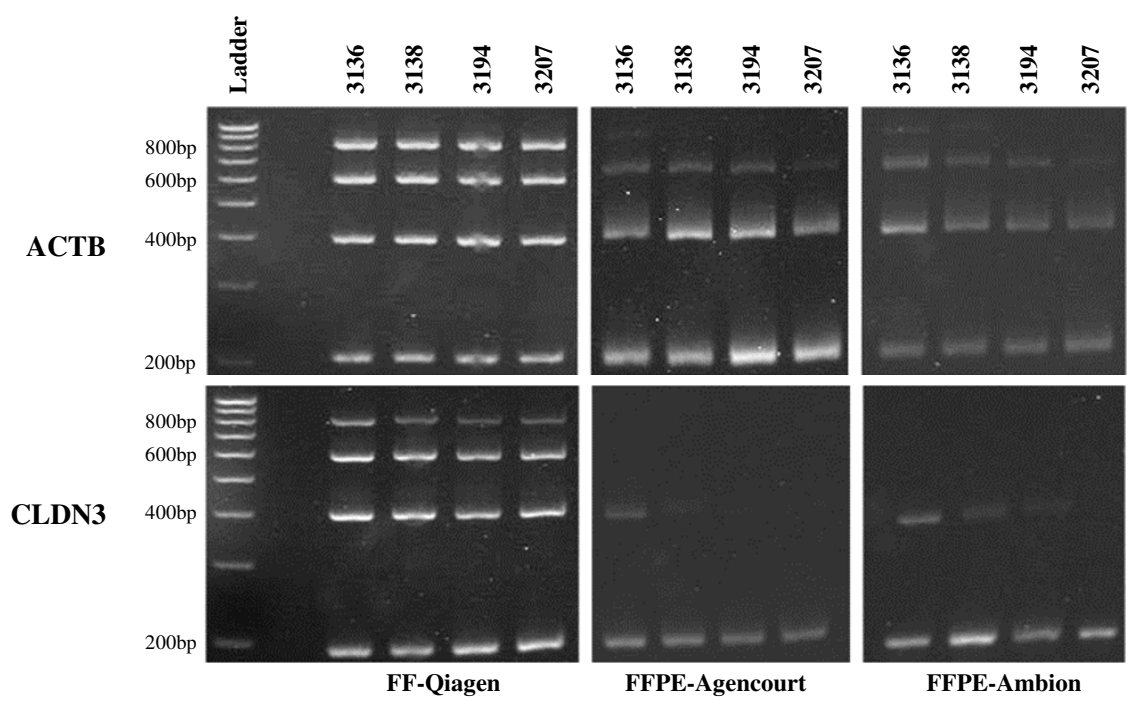

\section{Figure 2}

RT-PCR amplification of different fragment sizes (200, 400, 600 and 800 bp) of ACTB and CLDN3 genes in FF and matched FFPE ovarian adenocarcinoma samples $3136,3138,3194$, and 3207 . The method used for RNA extraction is indicated next to each sample type.

shown). For the remaining four FFPE samples, amplification of $200 \mathrm{bp}, 400 \mathrm{bp}$ and $600 \mathrm{bp}$ fragments was achieved for the $A C T B$ gene. For CLDN3, the $200 \mathrm{bp}$ amplicon was detected in four FFPE samples. The $400 \mathrm{bp}$ fragment was detected in two samples (3136 and 3138); one additional sample that was processed with the Ambion method (3194) showed weak presence of this amplicon, suggesting that it may have more intact RNA compared to the Agencourt counterpart. In contrast to $A C T B, C L D N 3$ amplicons $>400$ bp were not detected in any of the FFPE samples.

cRNA yields from FF samples averaged at $12.5 \mu \mathrm{g}$, while those from FFPE samples ranged from 2.2 to $6.1 \mu \mathrm{g}$. This illustrates greater dependence of cRNA yield on RNA quality than on quantity since equal amounts of total RNA were used to generate cRNAs. High specific activities ranging from 10.9 to $13.6 \mathrm{pmol} \mathrm{Cy} 5 / \mu \mathrm{g}$ were observed for cRNAs from FF samples. The corresponding FFPE samples resulted in noticeably lower specific activities ranging from 1.6 to $7.6 \mathrm{pmol}$ Cy5/ $\mu \mathrm{g}$ cRNA. FFPE sample $390 \mathrm{had}$ the lowest dye incorporation compared to all other sam-

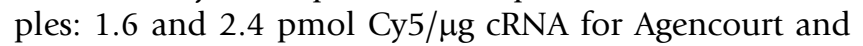
Ambion, respectively. Based on this result, as well as on poor RNA quality described above, FFPE sample 390 was expected to perform poorly in subsequent expression profiling.

Similar to the quality assessment of total RNA, labeled cRNA was also examined on the 2100 Bioanalyzer (Figure $1 \mathrm{~B})$. The size distribution of cRNA was very different when comparing electropherograms obtained from FF and FFPE samples. In FF samples, cRNAs showed a wide profile encompassing molecular weight size above $4000 \mathrm{nt}$, with the highest frequency of fragments in 200 nt range. In contrast, cRNAs generated from FFPE samples had narrow profiles of up to $\sim 1000 \mathrm{nt}$, with the highest frequency of fragments in $\sim 100 \mathrm{nt}$ range. Similar to the initial total RNA profile, cRNA for sample 390 showed a very narrow distribution range and lacked fragments above 500 nt.

\section{Gene expression profiling}

Reproducibility of genome-wide expression profiling of FF and FFPE samples was calculated using Pearson correlations (r). As shown in Figure 3, high reproducibility across replicates was observed regardless of the sample type. The $r$ value for "passing" probes (see Methods) ranged from 0.988 to 0.991 within FF replicates and from 0.983 to 0.985 within FFPE replicates. Although both FF and FFPE samples displayed similar $\mathrm{r}$ values, scatter graphs obtained by plotting $\log _{2}$ ratio values of FF replicates appeared tighter compared to the FFPE replicates. The lowest number of passing probes was observed in FFPE sample 390; this was not surprising since this sample was classified as inadequate for expression profiling based on the quality of RNA and cRNA. Thus, sample 390 was not taken into account in subsequent analyses.

Z-score analysis was used to determine the level of concordance between matched FF and FFPE-Agencourt samples. As shown in Figure 4A, the three selection criteria showed progressively increasing correlations and decreas- 


\begin{tabular}{cccc} 
& & & \\
& Sample & r & \# probes \\
\cline { 2 - 4 } FF & 3136 & 0.988 & 19049 \\
& 3138 & 0.989 & 19298 \\
& $\mathbf{3 1 9 4}$ & $\mathbf{0 . 9 9 0}$ & $\mathbf{2 1 2 9 4}$ \\
& 3207 & 0.991 & 20259 \\
& 390 & 0.989 & 20727 \\
\cline { 2 - 4 } & & & \\
& Sample & r & \# probes \\
\cline { 2 - 4 } FFPE & 3136 & 0.984 & 17363 \\
& 3138 & 0.985 & 16872 \\
& $\mathbf{3 1 9 4}$ & $\mathbf{0 . 9 8 5}$ & $\mathbf{1 9 7 5 7}$ \\
& 3207 & 0.983 & 16164 \\
& 390 & 0.983 & 14189 \\
\hline & & &
\end{tabular}

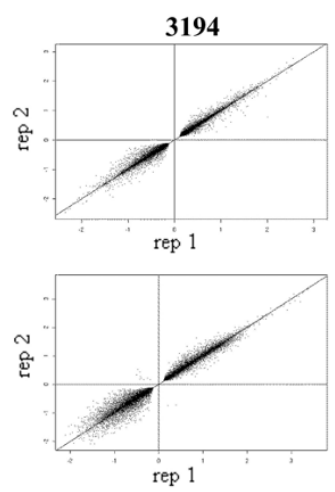

Figure 3

Reproducibility of gene expression profiling within FF and FFPE sample type. Pearson correlation value $(r)$ and number of "passing" probes are listed for samples 3136 , $3138,3194,3207$ and 390. Scatter graphs of $\log _{2}$ ratios comparing two FF (top) and two FFPE replicates (bottom) are shown for sample 3194.

ing misclassification rates, with the "100 DE" criterion achieving the best concordance. Sample 3138 showed the lowest concordance between its FF and FFPE z-scores, achieving a correlation of 0.553 and misclassification rate of $33 \%$. However, the remaining samples showed relatively high correlations ranging from 0.743 to 0.837 and misclassification rates of $2-15 \%$. The scatter plots of FF and FFPE Z-scores (Figure 4B) indicate that the three filtering criteria place tighter bounds on the analyses and the Zscores for probe sets obtained under the "1000 Cy5" and "100 DE" criteria fall close to the diagonal axes. These two criteria also produce qualitatively better results with the differentially expressed probes found predominantly in the first and third quadrants of the plots.

Microarray gene expression profiles from ovarian tumor samples were also compared to those of normal ovary tissue. The analysis of four patient samples, including FF as well as FFPE samples processed by the Ambion and Agencourt methods, identified 56 genes whose expression was at least two-fold higher in tumor than in normal ovary. Table 1 lists tumor-to-normal ratios obtained from the FF and FFPE-Agencourt samples. Thirty three out of these 56 genes have been previously associated with various cancers and include cell cycle regulatory genes CDC6 [27], CDT1 [28] and DTL [29]. A well known marker of ovarian serous carcinoma, CLDN3, appeared at the top of the list. In contrast, the probe for CA125 was not classified as "passing" in all of the samples and thus it is not included in the list. Several other genes, including TACSTD1 [3], PRAME [30] and ERBB4 [31], have been linked to ovarian tumorigenesis. PAX8 has been recently reported as a useful marker for the differentiation between ovarian and metastasized breast carcinoma [32]. Finally, the remain- ing genes that we identified as overexpressed in tumor samples may potentially represent some novel markers of ovarian cancer.

\section{Discussion}

FFPE samples are a desirable source of archival material for gene expression profiling studies due to their availability and the possibility of retrospective studies. At present, great variability is still being observed between gene expression profiles of matched FF and FFPE samples. Sample source and its classification, as well as the conditions used to fix and store samples, are some of many possible variables influencing gene expression. For example, a study relying on controlled fixation conditions to process bone marrow cells reported that FFPE samples appeared very similar to those of unfixed frozen equivalents [14]. However, controlled fixation procedure and use of cells may not represent an optimal approach to demonstrate the performance of archived FFPE tissue samples. Unsurprisingly, we have previously observed that FFPE cell pellets dissociated faster during Proteinase $\mathrm{K}$ digestion and often resulted in better RNA quality compared to FFPE tissues.

FFPE samples are routinely prepared by fixing tissues in $10 \%$ neutral-buffered formalin for 12 to 24 hours at ambient temperature. The FFPE samples used in this study, except for sample 390, were fixed in formalin for 4 to 18 hours at $4^{\circ} \mathrm{C}$. These samples appear to perform better than sample 390 which was fixed using routine conditions. Thus, it appears that shorter time and lower temperature of fixation can significantly affect FFPE sample quality. Other variables such as size of collected tissue, time elapsed to fixation and storage time could have further affected this outcome [33,34]. Regarding storage time, we have noticed that ribosomal RNA peaks could be detected in FFPE samples that were stored properly for up to one year and not for longer periods of time (data not shown).

Two commercially available FFPE RNA isolation kits, Ambion Optimum and Agencourt FormaPure, were tested here for extracting RNA from five FFPE ovarian serous adenocarcinoma samples. Sufficient amounts of total RNA for gene expression profiling were achieved by processing two to eight FFPE sections per patient. Despite pooling multiple sections, the RNA yields from FFPE samples were always significantly lower compared to those obtained from FF samples (data not shown). In addition, the obtained RNA amount was not proportional to the surface area of tissues used for RNA extraction. Although significant necrosis was not detected in any of the sections, we noticed differences in tissue density and composition. For example, presence of vasculature and adipose was detected in some sections and undoubtedly affected the 
A

\begin{tabular}{ccccccc} 
& \multicolumn{2}{c}{ All probes } & \multicolumn{2}{c}{ "1000 Cy5" } & \multicolumn{2}{c}{ "100 DE" } \\
Sample & Correlation & Misclass. & Correlation & Misclass. & Correlation & Misclass. \\
\hline $\mathbf{3 1 3 6}$ & 0.343 & 0.397 & 0.536 & 0.340 & 0.792 & 0.060 \\
$\mathbf{3 1 3 8}$ & 0.112 & 0.476 & 0.259 & 0.465 & 0.553 & 0.333 \\
$\mathbf{3 1 9 4}$ & 0.348 & 0.396 & 0.467 & 0.361 & 0.837 & 0.020 \\
$\mathbf{3 2 0 7}$ & 0.214 & 0.431 & 0.457 & 0.370 & 0.743 & 0.150
\end{tabular}

B
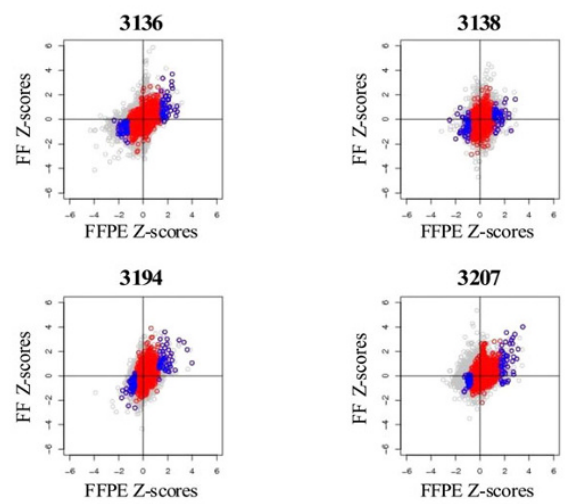

\section{Figure 4}

Z-score analyses comparing FFPE and FF samples. Pearson correlation and misclassification rate $(\mathbf{A})$ as well as scatter plots of Z-score values (B) for samples 3136,3138 , 3194 and 3207 are shown for "All probes" (in grey), "I000 Cy5" (in red) and "I00 DE" (in blue) probe selection criteria.

amounts of recovered nucleic acids. With respect to tissue content, all FFPE samples used in this study were required to contain $70-85 \%$ tumor cells, ensuring that they truly represented ovarian serous adenocarcinomas.

Two quality control assays, the Agilent 2100 Bioanalyzer and RT-PCR, were employed to assess the integrity of RNA obtained from FF and FFPE samples. Although RNA profiles from FFPE samples lacked well defined $18 \mathrm{~S}$ and $28 \mathrm{~S}$ ribosomal peaks, the method was successful in identifying inadequate samples, such as sample 390, containing predominantly small molecular weight fragments (<200 nt). Our RT-PCR assay tested the RNA for the presence of different size fragments of two genes, ACTB and CLDN3. Not surprisingly, we were not able to amplify any fragments in FFPE sample 390. Thus, the data synergy observed between the Bioanalyzer and the RT-PCR assay proved to be very useful in qualifying FFPE samples suitable for gene expression profiling on microarrays. These two assays also demonstrated that both the Ambion Optimum and the Agencourt FormaPure methods were successful in obtaining RNA of similar quality. Together, the combination of quality control methods used here should be effective in recognizing poor-performing FFPE samples and could be used to prevent unnecessary array hybridizations. A different method for identifying unacceptable FFPE samples has been described by NuGEN Technologies [35].
Gene expression profiling data of ovarian tumors demonstrated high correlations between replicate FF $(\geq 0.988)$ and FFPE samples $(\geq 0.983)$, illustrating good reproducibility of each method. Although reproducible, gene expression profiling of FFPE samples is affected by reduced number of "passing" probes (33-46\% compared to $44-49 \%$ in FF) and thus detects fewer differentially expressed genes compared to FF samples. Lassmann et al. recently reported similar findings by detecting 36\% and $50 \%$ of probes for FFPE and FF samples, respectively [20]. Our comparison between FF and their matched FFPE samples revealed the highest concordance of 0.84 for sample 3194. Although not directly comparable, a mean concordance of 0.86 was reported previously when comparing matched FF and FFPE samples on a different microarray platform [17]. Haque et al. reported a correlation of 0.65 between unmatched FF and FFPE pediatric glioblastomas [23]. While the magnitude of differential expression in FFPE samples might not be accurate, our Z-score analysis indicated that the direction of the change was correct in most cases, as demonstrated by low misclassification rates.

The comparison of ovarian serous adenocarcinoma to normal ovary identified 56 genes that are overexpressed in both FF and FFPE tumor samples. Several genes among them, including $C L D N 3$, were previously recognized for their roles in ovarian tumorigenesis, [2-5,30-32]; additional genes with unknown roles were also identified. Profiling of archival FFPE samples has been used previously to identify gene signatures that may serve as prognostic and diagnostic markers [20-24]. Regarding ovarian cancer, a set of 86 gene signatures that seems to predict overall survival was recently identified by microarray profiling [36]. Furthermore, 57 of these 86 genes were confirmed in an independent dataset [37]. Together, these findings suggest that archival FFPE samples can be successfully used to identify potentially novel disease markers. At the same time, it is recognized that gene expression profiling of FFPE samples on microarrays has some limitations. In our study, as well as in Van Deerlin et al. [38], the magnitude of differential expression was typically higher in FFPE than in FF samples, suggesting higher level of noise in the FFPE data. Therefore, the elimination of false positives and identification of subtle changes in gene expression in FFPE samples remain challenging, especially in studies lacking FF counterparts.

Technological improvements in handling FFPE samples are constantly evolving; some of them clearly lead towards better quality of microarray expression data. One such improvement entails a change in primers used during amplification. At present, commonly used procedures rely on oligo (dT) primers which introduce 3' end bias 
Table I: List of genes whose ratios are at least two-fold higher in ovarian serous adenocarcinoma compared to normal ovary.

\begin{tabular}{|c|c|c|c|c|}
\hline ProbeName & GeneName & Annotation & FF tumor/FF normal ratio & FFPE tumor/FF normal ratio \\
\hline A_23_P9108I & TACSTDI & $\begin{array}{l}\text { tumor-associated calcium signal } \\
\text { transducer I (TACSTDI), mRNA } \\
\text { [NM_002354] }\end{array}$ & 43.7 & 5.1 \\
\hline A_23_PII8894 & ATAD4 & $\begin{array}{l}\text { ATPase family, AAA domain containing } 4 \\
\text { (ATAD4), mRNA [NM_024320] }\end{array}$ & 25.1 & 20.4 \\
\hline A_23_P71017 & CLDN3 & $\begin{array}{l}\text { claudin } 3 \text { (CLDN3), mRNA } \\
\text { [NM_00|306] }\end{array}$ & 20.4 & 77.2 \\
\hline A_23_PI24335 & THC2539702 & $\begin{array}{l}\text { Q9F8M7_CARHY (Q9F8M7) DTDP- } \\
\text { glucose 4,6-dehydratase (Fragment), } \\
\text { [THC254698I] }\end{array}$ & 20.0 & 22.2 \\
\hline A_24_P4III86 & BCLIIA & $\begin{array}{l}\text { B-cell CLL/lymphoma I I A (zinc finger } \\
\text { protein) (BCLIIA), transcript variant } \\
\text { I, mRNA [NM_022893] }\end{array}$ & 18.7 & 14.8 \\
\hline A_24_P273647 & LOCI 46439 & $\begin{array}{l}\text { mRNA; cDNA DKFZp666LI66 (from clone } \\
\text { DKFZp666LI 166). [AL833749] }\end{array}$ & 17.5 & 95.5 \\
\hline A_23_P39305I & Clorfl 72 & $\begin{array}{l}\text { chromosome I open reading frame } 172 \\
\text { (ClorfI72), mRNA [NM_I52365] }\end{array}$ & 16.9 & 18.0 \\
\hline A_24_PI53713 & MARVELD3 & $\begin{array}{l}\text { MARVEL domain containing } 3 \\
\text { (MARVELD3), transcript variant I, } \\
\text { mRNA [NM_00 I0I7967] }\end{array}$ & 14.4 & 34.7 \\
\hline A_24_P57977 & SNIP & $\begin{array}{l}\text { SNAP25-interacting protein (SNIP), } \\
\text { mRNA [NM_025248] }\end{array}$ & 12.6 & 32.1 \\
\hline A_23_P83339 & RNFI83 & $\begin{array}{l}\text { ring finger protein I83 (RNFI83), mRNA } \\
\text { [NM_I4505I] }\end{array}$ & 11.1 & 36.2 \\
\hline A_23_P50096 & TYMS & $\begin{array}{l}\text { thymidylate synthetase (TYMS), } \\
\text { mRNA [NM_00107I] }\end{array}$ & 11.1 & 3.0 \\
\hline A_23_P335II & $A \times 721087$ & $\begin{array}{l}\text { Incyte sequence } 47 \text { from Patent } \\
\text { WO0220754. [AX721087] }\end{array}$ & 11.0 & 23.4 \\
\hline A_23_PI6348I & BUBIB & $\begin{array}{l}\text { BUB I budding uninhibited by } \\
\text { benzimidazoles I homolog beta } \\
\text { (yeast) (BUB IB), mRNA } \\
\text { [NM_00IIII] }\end{array}$ & 10.2 & 4.3 \\
\hline A_32_P57013 & BU540282 & $\begin{array}{l}\text { AGENCOURT_I0326456 NIH_MGC_I4I I } \\
\text { cDNA clone IMAGE:657I } 6865^{\prime}, \text { mRNA } \\
\text { [BU540282] }\end{array}$ & 10.0 & 105.4 \\
\hline A_23_P319859 & EYA2 & $\begin{array}{l}\text { eyes absent homolog } 2 \text { (Drosophila) } \\
\text { (EYA2), transcript variant 2, mRNA } \\
\text { [NM_172I13] }\end{array}$ & 9.9 & 4.2 \\
\hline A_32_PI83765 & ERBB4 & $\begin{array}{l}\text { v-erb-a erythroblastic leukemia viral } \\
\text { oncogene homolog } 4 \text { (avian) (ERBB4), } \\
\text { mRNA [NM_005235] }\end{array}$ & 9.6 & 8.6 \\
\hline A_23_P38586I & CDCA2 & $\begin{array}{l}\text { cell division cycle associated } 2 \\
\text { (CDCA2), mRNA [NM_I52562] }\end{array}$ & 9.4 & 6.8 \\
\hline A_32_P46456 & THC264885I & $\begin{array}{l}\text { glucosidase, beta (bile acid) } 2 \text { (GBA2), } \\
\text { mRNA [NM_020944] }\end{array}$ & 9.4 & 22.0 \\
\hline A_32_P30874 & AJ420543 & $\begin{array}{l}\text { mRNA full length insert cDNA clone } \\
\text { EUROIMAGE } 1090207 \text {. [A]420543] }\end{array}$ & 9.3 & 30.6 \\
\hline A_24_P402588 & BCLIIA & $\begin{array}{l}\text { B-cell CLL/lymphoma I IA (zinc finger } \\
\text { protein) (BCLI IA), transcript variant } \\
\text { I, mRNA [NM_022893] }\end{array}$ & 9.2 & 31.1 \\
\hline A_23_P21000I & PAX8 & $\begin{array}{l}\text { paired box gene } 8 \text { (PAX8), transcript } \\
\text { variant PAX8A, mRNA [NM_003466] }\end{array}$ & 8.4 & 31.3 \\
\hline A_32_PI36033 & AK090477 & mRNA for FLJ00399 protein. [AK090477] & 8.4 & 12.8 \\
\hline A_23_PI66508 & BC038245 & clone IMAGE:524I654, mRNA. [BC038245] & 7.9 & 9.1 \\
\hline A_23_PI8579 & PTTG2 & $\begin{array}{l}\text { pituitary tumor-transforming } 2 \\
\text { (PTTG2), mRNA [NM_006607] }\end{array}$ & 7.5 & 7.8 \\
\hline A_23_P78958 & CAPS & $\begin{array}{l}\text { calcyphosine (CAPS), transcript variant I, } \\
\text { mRNA [NM_004058] }\end{array}$ & 7.2 & 11.1 \\
\hline A_23_P724II & CYP4XI & $\begin{array}{l}\text { cytochrome P450, family } 4 \text {, subfamily X, } \\
\text { polypeptide I (CYP4XI), mRNA } \\
\text { [NM 178033] }\end{array}$ & 7.2 & 4.0 \\
\hline A_32_PI5I 244 & AK022268 & $\begin{array}{l}\text { CDNA FLJI } 2206 \text { fis, clone } \\
\text { MAMMAI00094I. [AK022268] }\end{array}$ & 7.0 & 22.2 \\
\hline A_23_PI0385' & DTL & $\begin{array}{l}\text { denticleless homolog (Drosophila) } \\
\text { (DTL), mRNA [NM_0|16448] }\end{array}$ & 6.5 & 5.4 \\
\hline A_23_P68669 & CHODL & $\begin{array}{l}\text { chondrolectin (CHODL), mRNA } \\
\text { [NM_024944] }\end{array}$ & 6.4 & 9.6 \\
\hline A_32_PI 48745 & FLJ $147 / 2$ & $\begin{array}{l}\text { CDNA FL I } 47 \mid 2 \text { fis, clone NT2RP3000825. } \\
\text { [AK0276 I8] }\end{array}$ & 6.1 & 3.3 \\
\hline A_23_PI51915 & GCNT3 & $\begin{array}{l}\text { glucosaminyl (N-acetyl) transferase 3, mucin } \\
\text { type. Acc:NP_004742] [ENST00000267857] }\end{array}$ & 5.9 & 11.9 \\
\hline A_32_P77933 & FLJ22795 & $\begin{array}{l}\text { colon cancer-associated antigen } \\
\text { AgSKI-2HT-ECS mRNA, complete } \\
\text { cds. [AF3 | } 6855]\end{array}$ & 5.9 & 24.1 \\
\hline
\end{tabular}


Table I: List of genes whose ratios are at least two-fold higher in ovarian serous adenocarcinoma compared to normal ovary. (Continued)

\begin{tabular}{|c|c|c|c|c|}
\hline A_23_P31073 & MYB & $\begin{array}{l}\text { v-myb myeloblastosis viral oncogene } \\
\text { homolog (avian) (MYB), mRNA } \\
\text { [NM_005375] }\end{array}$ & 5.5 & 24.8 \\
\hline A_23_P28953 & DNMT3B & $\begin{array}{l}\text { DNA (cytosine-5-)-methyltransferase } \\
3 \text { beta (DNMT3B), transcript variant } \\
6, \text { mRNA [NM_175850] }\end{array}$ & 5.3 & 8.9 \\
\hline A_32_PII7I86 & CR749547 & $\begin{array}{l}\text { mRNA; cDNA DKFZp686] I7III0 (from } \\
\text { clone DKFZp686] I7I I0) [CR749547] }\end{array}$ & 5.0 & 4.1 \\
\hline A_32_PI 28558 & FLJ22795 & $\begin{array}{l}\text { colon cancer-associated antigen } \\
\text { AgSK I-2HT-ECS mRNA, complete } \\
\text { cds. [AF3।6855] }\end{array}$ & 4.8 & 15.7 \\
\hline A_23_PI66360 & PRAME & $\begin{array}{l}\text { preferentially expressed antigen in } \\
\text { melanoma (PRAME), transcript } \\
\text { variant 5, mRNA [NM_206956] }\end{array}$ & 4.5 & 3.1 \\
\hline A_23_PI 103720 & AGMAT & $\begin{array}{l}\text { agmatine ureohydrolase (agmatinase) } \\
\text { (AGMAT), mRNA [NM_024758] }\end{array}$ & 4.3 & 2.8 \\
\hline A_23_P42935 & BRAF & $\begin{array}{l}\text { v-raf murine sarcoma viral oncogene } \\
\text { homolog BI (BRAF), mRNA } \\
\text { [NM_004333] }\end{array}$ & 4.2 & 3.6 \\
\hline A_24_P74I023 & $B C 008476$ & cDNA clone IMAGE:4290767. [BC008476] & 3.9 & 18.5 \\
\hline A_23_P49972 & $C D C 6$ & $\begin{array}{l}\text { cell division cycle } 6 \text { homolog (S. } \\
\text { cerevisiae) (CDC6), mRNA } \\
\text { [NM_00I254] }\end{array}$ & 3.9 & 4.7 \\
\hline A_24_P925I9I & THC2640472 & $\begin{array}{l}\text { Q2MIU4_HUMAN (Q2MIU4) Catalase, } \\
\text { partial (3I\%) [THC2640472] }\end{array}$ & 3.9 & 6.5 \\
\hline A_24_PI 453 I6 & DTNBPI & $\begin{array}{l}\text { dystrobrevin binding protein I } \\
\text { (DTNBPI), transcript variant 2, } \\
\text { mRNA [NM_183040] }\end{array}$ & 3.8 & 5.9 \\
\hline A_23_PI9987 & IGF2BP3 & $\begin{array}{l}\text { insulin-like growth factor } 2 \text { mRNA } \\
\text { binding protein } 3 \text { (IGF2BP3), mRNA } \\
\text { [NM_006547] }\end{array}$ & 3.7 & 13.6 \\
\hline A_23_PI48768' & F5 & $\begin{array}{l}\text { coagulation factor V (proaccelerin, labile } \\
\text { factor) (F5), mRNA [NM_000130] }\end{array}$ & 3.6 & 78.1 \\
\hline A_23_P37704 & CDTI & $\begin{array}{l}\text { chromatin licensing and DNA } \\
\text { replication factor I (CDTI), mRNA } \\
\text { [NM_030928] }\end{array}$ & 3.5 & 7.5 \\
\hline A_24_P544543 & CAPNI & $\begin{array}{l}\text { CDNA FL] } 12257 \text { fis, clone } \\
\text { MAMMAI00150I, highly similar to } \\
\text { CALPAIN I. [AK022319] }\end{array}$ & 3.1 & 8.2 \\
\hline A_23_P89570 & ZMYNDI5 & $\begin{array}{l}\text { zinc finger, MYND-type containing } 15 \\
\text { (ZMYND I5), mRNA [NM_032265] }\end{array}$ & 2.9 & 11.8 \\
\hline A_24_P340659 & $A F 268613$ & $\begin{array}{l}\text { POU } 5 \text { domain protein (POU5FLCI) } \\
\text { mRNA, complete cds. [AF2686/3] }\end{array}$ & 2.8 & 3.1 \\
\hline A_24_P343095 & DHFR & $\begin{array}{l}\text { dihydrofolate reductase (DHFR), } \\
\text { mRNA [NM_00079I] }\end{array}$ & 2.8 & 2.6 \\
\hline A_24_P257099 & $D K F Z p 762 E / 3 \mid 2$ & $\begin{array}{l}\text { hypothetical protein DKFZp762E I3 I2 } \\
\text { (DKFZp762E|3|2), mRNA } \\
\text { [NM_0|84|0] }\end{array}$ & 2.7 & 2.9 \\
\hline A_23_PII 0957 & FOXF2 & $\begin{array}{l}\text { forkhead box F2 (FOXF2), mRNA } \\
\text { [NM_001452] }\end{array}$ & 2.7 & 3.9 \\
\hline A_23_P75260 & RASSF4 & $\begin{array}{l}\text { Ras association (RaIGDS/AF-6) } \\
\text { domain family } 4 \text { (RASSF4), mRNA } \\
\text { [NM_032023] }\end{array}$ & 2.6 & 7.4 \\
\hline A_32_P8II73 & USP34 & $\begin{array}{l}\text { mRNA; cDNA DKFZp586]10I (from clone } \\
\text { DKFZp586J10I). [AL050376] }\end{array}$ & 2.6 & 2.9 \\
\hline A_23_PI56807 & SDHAP3 & $\begin{array}{l}\text { succinate dehydrogenase complex, subunit } \\
\text { A, flavoprotein pseudogene } 3 \text { (SDHAP3) } \\
\text { [NR_003263] }\end{array}$ & 2.6 & 9.5 \\
\hline A_23_PI 09072 & SALL4 & $\begin{array}{l}\text { sal-like } 4 \text { (Drosophila) (SALL4), } \\
\text { mRNA [NM_020436] }\end{array}$ & 2.6 & 3.5 \\
\hline A_32_PI32563 & POU5FI & $\begin{array}{l}\text { POU domain, class } 5 \text {, transcription factor I } \\
\text { (POU5FI), transcript variant I, mRNA } \\
\text { [NM_00270I] }\end{array}$ & 2.5 & 10.8 \\
\hline A_23_P24870' & CD44 & $\begin{array}{l}\text { CD44 molecule (Indian blood group) } \\
\text { (CD44), transcript variant I, mRNA } \\
\text { [NM_0006 I } 0]\end{array}$ & 2.5 & 5.2 \\
\hline
\end{tabular}

Genes associated with cancer in previous reports are shown in bold. Fold change $\mathrm{P} \leq 0.05$. Genes are sorted according to descending $\mathrm{FF}$ tumor/nomal ratios.

IProbe is represented on microarrays multiple times; average of multiple measurements is reported here. 
$[17,39]$; consequently, most commercial microarrays have probes designed within the last several hundred bases of each transcript. A new amplification procedure, developed recently by NuGEN, utilizes random primers in addition to oligo (dT) primers, thus alleviating the 3 ' end bias. Initial studies suggest that such whole transcript amplification provides a significant advantage when processing FFPE samples $[14,20]$. Thus, this amplification method deserves further investigation and holds promise for improving the performance of FFPE samples in future microarray profiling studies.

\section{Conclusion}

Five matched FFPE and FF ovarian tumor samples were profiled on microarrays, illustrating the level of gene expression similarity between the two sample types. Ovarian tumor and normal samples were also compared, identifying a set of differentially expressed genes characteristic of ovarian adenocarcinoma. Conclusively, our study demonstrates that archived clinical samples, such as FFPE ovarian adenocarcinomas, represent a valuable source for genome-wide expression profiling and can be successfully used for the identification of potentially novel carcinoma markers. Further improvements in FFPE sample handling and new amplification approaches hold promise for even better performance of FFPE samples in future microarray studies.

\section{Competing interests}

The authors declare that they have no competing interests.

\section{Authors' contributions}

GF designed and carried out microarray experiments, SG and TDW performed data analyses and ZM conceived and directed the project. GF and ZM wrote the manuscript.

\section{Acknowledgements}

We would like to thank Susanna Stinson for optimizing the FFPE RNA extraction procedure, Deepali Bhatt for extracting normal ovary RNA, Human Tissue Bank and Pathology personnel for providing matched FF and FFPE serous adenocarcinomas, and the Oligo group for synthesizing primers.

\section{References}

I. Rosen DG, Wang L, Atkinson N, Yu Y, Lu KH, Diamandis EP, Hellstrom I, Mok SC, Liu J, Bast RC Jr: Potential markers that complement expression of CAI 25 in epithelial ovarian cancer. Gynecol Oncol 2005, 99:267-277.

2. Choi YL, Kim J, Kwon MJ, Choi JS, Kim TJ, Bae DS, Koh SS, In YH, Park YW, Kim SH, Ahn G, Shin YK: Expression profile of tight junction protein claudin 3 and claudin 4 in ovarian serous adenocarcinoma with prognostic correlation. Histol Histopathol 2007, 22: I 185-95.

3. Bignotti E, Tassi RA, Calza S, Ravaggi A, Romani C, Rossi E, Falchetti $M$, Odicino FE, Pecorelli S, Santin AD: Differential gene expression profiles between tumor biopsies and short-term primary cultures of ovarian serous carcinomas: Identification of novel molecular biomarkers for early diagnosis and therapy. Gynecol Oncol 2006, 103:405-416.
4. Peters DG, Kudla DM, Deloia JA, Chu TJ, Fairfull L, Edwards RP, Ferrell RE: Comparative gene expression analysis of ovarian carcinoma and normal ovarian epithelium by serial analysis of gene expression. Cancer Epidemiol Biomarkers Prev 2005, 14:1717-1723.

5. Hough CD, Sherman-Baust CA, Pizer ES, Montz FJ, Im DD, Rosenshein NB, Cho KR, Riggins GJ, Morin PJ: Large-scale serial analysis of gene expression reveals genes differentially expressed in ovarian cancer. Cancer Res 2000, 60:628I-7.

6. Krafft AE, Duncan BW, Bijwaard KE, Taubenberger JK, Lichy JH: Optimization of the isolation and amplification of RNA from formalin-fixed, paraffin-embedded tissue: The Armed Forces Institute of Pathology Experience and Literature Review. Mol Diagn 1997, 2:217-230.

7. Masuda N, Ohnishi T, Kawamoto S, Monden M, Okubo K: Analysis of chemical modification of RNA from formalin-fixed samples and optimization of molecular biology application for such samples. Nucleic Acids Res 1999, 27:4436-4443.

8. Stanta G, Mucelli SP, Petrera F, Bonin S, Bussolati G: A novel fixative improves opportunities of nucleic acids and proteomic analysis in human archive's tissues. Diagn Mol Pathol 2006, 15: I15-123.

9. Specht K, Richter T, Müller U, Walch A, Werner M, Höfler H: Quantitative gene expression analysis in microdissected archival formalin-fixed and paraffin-embedded tumor tissue. Am J Pathol 200I, I 58:419-429.

10. Cronin M, Pho M, Dutta D, Stephans JC, Shak S, Kiefer MC, Esteban JM, Baker JB: Measurement of gene expression in archival paraffin-embedded tissues: development and performance of a 92-gene reverse transcriptase-polymerase chain reaction assay. Am J Pathol 2004, 164:35-42.

II. Gloghini A, Canal B, Klein U, Dal Maso L, Perin T, Dalla-Favera R, Carbone A: RT-PCR analysis of RNA extracted from Bouinfixed and paraffin-embedded lymphoid tissues. I Mol Diagn 2004, 6:290-296.

12. Pagedar NA, Wang W, Chen DH, Davis RR, Lopez I, Wright CG, Alagramam $\mathrm{KN}$ : Gene expression analysis of distinct populations of cells isolated from mouse and human inner ear FFPE tissue using laser capture microdissection - a technical report based on preliminary findings. Brain Res 2006, 1091:289-299.

13. Hamatani K, Eguchi H, Takahashi K, Koyama K, Mukai M, Ito R, Taga M, Yasui W, Nakachi K: Improved RT-PCR amplification for molecular analyses with long-term preserved formalin-fixed, paraffin-embedded tissue specimens. J Histochem Cytochem 2006, 54:773-780.

14. Scicchitano MS, Dalmas DA, Bertiaux MA, Anderson SM, Turner LR, Thomas RA, Mirable R, Boyce RW: Preliminary comparison of quantity, quality, and microarray performance of RNA extracted from formalin-fixed, paraffin-embedded, and unfixed frozen tissue samples. J Histochem Cytochem 2006, 54: 1229- 1237

15. Coudry RA, Meireles SI, Stoyanova R, Cooper HS, Carpino A, Wang $X$, Engstrom PF, Clapper ML: Successful application of microarray technology to microdissected formalin-fixed, paraffinembedded tissue. J Mol Diagn 2007, 9:70-79.

16. Karsten SL, Van Deerlin VMD, Sabatti C, Gill LH, Geschwind DH: An evaluation of tyramide signal amplification and archived fixed and frozen tissue in microarray gene expression analysis. Nucleic Acids Res 2002, 30:e4.

17. Frank M, Döring C, Metzler D, Eckerle S, Hansmann ML: Global gene expression profiling of formalin-fixed paraffin-embedded tumor samples: a comparison to snap-frozen material using oligonucleotide microarrays. Virchows Arch 2007, 450:699-7II.

18. Linton KM, Hey Y, Saunders E, Jeziorska M, Denton J, Wilson CL, Swindell R, Dibben S, Miller CJ, Pepper SD, Radford JA, Freemont AJ: Acquisition of biologically relevant gene expression data by Affymetrix microarray analysis of archival formalin-fixed paraffin-embedded tumours. BrJ Cancer 2008, 98: 1403-I4|4.

19. Penland SK, Keku TO, Torrice C, He X, Krishnamurthy J, Hoadley KA, Woosley JT, Thomas NE, Perou CM, Sandler RS, Sharpless NE: RNA expression analysis of formalin-fixed paraffin-embedded tumors. Lab Invest 2007, 87:383-39I.

20. Lassmann S, Kreutz C, Schoepflin A, Hopt U, Timmer J, Werner M: A novel approach for reliable microarray analysis of micro- 
dissected tumor cells from formalin-fixed and paraffinembedded colorectal cancer resection specimens. J Mol Med 2009, 87:2II-24.

21. Chung CH, Parker JS, Ely K, Carter J, Yi Y, Murphy BA, Ang KK, ElNaggar AK, Zanation AM, Cmelak AJ, Levy S, Slebos RJ, Yarbrough WG: Gene expression profiles identify epithelial-to-mesenchymal transition and activation of nuclear factor-(kappa)B signaling as characteristics of a high-risk head and neck squamous cell carcinoma. Cancer Res 2006, 66:8210-8218.

22. Onken MD, Worley LA, Ehlers JP, Harbour JW: Gene expression profiling in unveal melanoma reveals two molecular classes and predicts metastatic death. Cancer Res 2004, 64:7205-7209.

23. Haque T, Faury D, Albrecht S, Lopez-Aquilar E, Hauser P, Garami M, Hanzély Z, Bognár L, Del Maestro RF, Atkinson J, Nantel A, Jabado N: Gene expression profiling from formalin-fixed paraffinembedded tumors of pediatric glioblastoma. Clin Cancer Res 2007, I 3:6284-6292.

24. Rogerson L, Darby S, Jabbar T, Mathers ME, Leung HY, Robson CN, Sahadevan K, O'Toole K, Gnanapragasam VJ: Application of transcript profiling in formalin-fixed paraffin-embedded diagnostic prostate cancer needle biopsies. BJU Int 2008, 102:364-370.

25. Cheadle C, Vawter MP, Freed WJ, Becker KG: Analysis of microarray data using $\mathbf{Z}$ score transformation. J Mol Diagn 2003, 5:73-8I.

26. Baldi $P$, Long $A D$ : A Bayesian framework for the analysis of microarray expression data: regularized t-test and statistical inferences of gene changes. Bioinformatics 200I, 17:509-5I9.

27. Borlado LR, Mendez J: CDC6: from DNA replication to cell cycle checkpoints and oncogenesis. Carcinogenesis 2008, 29:237-243.

28. Liontos M, Koutsami M, Sideridou M, Evangelou K, Kletsas D, Levy B, Kotsinas A, Nahum O, Zoumpourlis V, Kouloukoussa M, Lygerou Z, Taraviras S, Kittas C, Bartkova J, Papavassiliou AG, Bartek J, Halazonetis TD, Gorgoulis VG: Deregulated overexpression of hCdt I and hCdc6 promotes malignant behaviour. Cancer Res 2007, 67:10899-10909.

29. Sansam CL, Shepard JL, Lai K, lanari A, Danielian PS, Amsterdam A, Hopkins N, Lees JA: DTL/CDT2 is essential for both CDTI regulation and the early G2/M checkpoint. Genes Dev 2006, 20:3117-3129.

30. Giordano TJ, Shedden KA, Schwartz DR, Kuick R, Taylor JM, Lee N, Misek DE, Greenson JK, Kardia SL, Beer DG, Rennert G, Cho KR, Gruber SB, Fearon ER, Hanash S: Organ-specific molecular classification of primary lung, colon, and ovarian adenocarcinomas using gene expression profiles. Am 」 Pathol 200I, I59:123I-1238.

31. Gilmour LM, Macleod KG, McCaig A, Gullick WJ, Smyth JF, Langdon SP: Expression of erbB-4/HER-4 growth factor receptor isoforms in ovarian cancer. Cancer Res 2001, 61:2169-2176.

32. Nonaka D, Chiriboga L, Soslow RA: Expression of Pax8 as a useful marker in distinguishing ovarian carcinomas from mammary carcinomas. Am J Surg Pathol 2008, 32:1566-I57I.

33. Gruber AD, Moennig V, Hewicker-Trautwein M, Trautwein G: Effect of formalin fixation and long-term storage on the detectability of bovine viral-diarrhoea-virus (BVDV) RNA in archival brain tissue using polymerase chain reaction. Zentralbl Veterinarmed B 1994, 41:654-66I.

34. Macabeo-Ong M, Ginzinger DG, Dekker N, McMillan A, Regezi JA, Wong DT, Jordan RC: Effect of duration of fixation on quantitative reverse transcription polymerase chain reaction analyses. Mod Pathol 2002, 15:979-987.

35. The NuGEN website [http://www.nugeninc.com/tasks/sites/
(n) nugen/assets/File/technical documents/ techdoc wt ov ffpe rep 0I.pdf

36. Crijns AP, Fehrmann RS, de Jong S, Gerbens F, Meersma GJ, Klip HG Hollema H, Hofstra RM, Meerman G], de Vries EG, Zee AG van der: Survival-related profile, pathways, and transcription factors in ovarian cancer. PLoS Med 2009, 6:e24.

37. Dressman HK, Berchuck A, Chan G, Zhai J, Bild A, Sayer R, Cragun J, Clarke J, Whitaker RS, Li L, Gray J, Marks J, Ginsburg GS, Potti A West M, Nevins JR, Lancaster JM: An integrated genomic-based approach to individualized treatment of patients with advanced-stage ovarian cancer. / Clin Oncol 2007, 25:5 17-525.

38. Van Deerlin VM, Gill LH, Nelson PT: Optimizing gene expression analysis in archival brain tissue. Neurochem Res 2002, 27:993-1003.
39. Srivastava PK, Küffer S, Brors B, Shahi P, Li L, Kenzelmann M, Gretz N, Gröne HJ: A cut-off based approach for gene expression analysis of formalin-fixed and paraffin-embedded tissue samples. Genomics 2008, 91 1:522-529.

\section{Pre-publication history}

The pre-publication history for this paper can be accessed here:

http://www.biomedcentral.com/1755-8794/2/23/prepub
Publish with Bio Med Central and every scientist can read your work free of charge

"BioMed Central will be the most significant development for disseminating the results of biomedical research in our lifetime. "

Sir Paul Nurse, Cancer Research UK

Your research papers will be:

- available free of charge to the entire biomedical community

- peer reviewed and published immediately upon acceptance

- cited in PubMed and archived on PubMed Central

- yours - you keep the copyright 